\title{
Current data about localization of acute ischemic stroke and prognostic factors in diabetic and non-diabetic patients
}

\author{
Nicolae Ovidiu POP ${ }^{1,2}$, Petru Aurel BABES 3 , Larisa Bianca HOLHOS ${ }^{4}$, Eugenia GAVRILUT ${ }^{3}$, \\ Gabriel Mihai MEKERES ${ }^{5}$, Mariana MEKERES-RACOVITA ${ }^{6}$, \\ Cristian VOITA NUTU ${ }^{6}$, Alina Oana IACOB-CUCIAN ${ }^{7}$ \\ ${ }^{1}$ Intensive Care Anesthesia Clinic, County Emergency Clinical Hospital, Oradea, Romania \\ ${ }^{2}$ Department of Surgical Disciplines, Faculty of Medicine and Pharmacy, University of Oradea, Romania \\ ${ }^{3}$ Faculty of Medicine and Pharmacy, University of Oradea, Romania \\ ${ }^{4}$ Department of Morphological Disciplines, Faculty of Medicine and Pharmacy, University of Oradea, Romania \\ ${ }^{5}$ Department of Medical Disciplines, Faculty of Medicine and Pharmacy, University of Oradea, Romania \\ ${ }^{6}$ Faculty of Medicine and Pharmacy, University of Oradea, Romania \\ ${ }^{7}$ County Emergency Clinical Hospital, Tg. Mures, Romania
}

\begin{abstract}
Introduction. Ischemic stroke accounts for approximately $85 \%$ of all vascular accidents and has a high number of identified risk factors, including transient ischemic attack, smoking, metabolic syndrome, alcohol consumption, elevated cholesterol levels and artery stenosis carotid. Diabetes mellitus (DM) is a well-established risk factor for ischemic stroke.

Material and method. This prospective longitudinal observational study highlights the importance of localization of ischemic stroke, including 340 patients with acute ischemic stroke with / without diabetes mellitus. The database was collected in a Microsoft Excel document. The correlation analysis was processed in the MedCalc 14.1 program where correlation tests included in the program were used.

Results. The predominant localization of ischemic stroke in diabetic patients was the middle cerebral artery followed by the posterior cerebral artery and the double localization compared to the group witness where the same trend is maintained ( $p=0.22$ ). The correlation between the localization of the acute ischemic stroke with the age 64.5 for MCA, 64.6 for PCA, and 73.57 for DL (CI 95\%, $p=0.02)$. The correlation of the NIHSS severity score with the location of ischemic strokes was also obtained: average NIHSS score 18.9 points for MCA, 18.5 for PCA, 24 for DL (CI 95, $p<0.0001$ ). The data obtained from the Kaplan-Meier analysis on the survival rate of the patients (divided by the vascular territory involved), provided an expected result difference (statistically significant, $p<0.0001$ ).

Conclusions. There is no statistically significant difference between diabetic vs. non-diabetic patients regarding the localization correlated with DM, the double location being statistically insignificant between the two batches. The double location having a higher frequency in elderly patients.
\end{abstract}

Keywords: diabetes, non-diabetes, ischemic stroke, prognosis 


\section{INTRODUCTION}

In developed countries, stroke is the third cause of mortality, followed by neoplastic and cardiovascular diseases. Increased risk is often seen in people with diabetes and is associated with weaker clinical outcomes (including higher mortality), so, the evaluation of the risk factors and prognosis for stroke are of utmost importance in patients' evolution.

Ischemic stroke accounts for approximately $85 \%$ of all vascular accidents [1] and has a high number of identified risk factors, including transient ischemic attack, smoking, metabolic syndrome, alcohol consumption, elevated cholesterol levels and artery stenosis carotid [2]. Also, diabetes mellitus (DM) is a well-established risk factor for ischemic stroke [3]. In addition, diabetes is considered a cerebrovascular risk factor, associated with increased mortality in the hospital, in patients with ischemic stroke [4-7]. Despite the improvement in primary prevention and acute treatment over the past decades, the stroke is still a devastating disease. At the beginning of the 21st century, the incidence of strokes in Europe ranged from 95 to 290 / 100,000 inhabitants / year, with a mortality rates / month of 13-35\% [8]. Approximately 1.1 million Europeans have suffered a stroke in each year, $80 \%$ of being of ischemic type. Although the incidence of stroke worldwide is in decline, the incidence of vascular accident in young people is increasing. Due to the aging population the number of strokes is expected to increase drastically in the next few years to $2025,1.5$ million Europeans will suffer an annual stroke $[9,10]$. Managing the risk factors of stroke should prolong or prevent the incident of acute thrombotic stroke since most of the patients with type 2 diabetes mellitus came to the hospital with a condition of hyperglycemia and hypertension [11].

Anterior and posterior circulation ischemic stroke have different natural histories, these regional differences in the prevalence of individual risk factors might also affect the case fatality rates for ischemic stroke. Furthermore, targeting individual risk factor modification at a population level (e.g. DM or atrial fibrillation) may exact both a quantitative and qualitative effect on stroke incidence [12]. Intracranial atherosclerosis of the anterior circulation and intracranial atherosclerosis of the posterior circulation are thought to involve different pathogeneses and risk factors $[13,14]$.

Stroke mechanisms differ according to the location of cerebral atherosclerosis. Because perforators are directly branched out of intracranial atherosclerosis, it is understandable that intracranial atherosclerosis produces strokes more often by way of local branch occlusion. In addition, in situ thrombo-occlusion is more common in patients with intracranial atherosclerosis, probably because of relatively sufficient collateral circulation through the posterior communicating artery, anterior communicating artery, and external carotid artery in patients with extracranial atherosclerosis. However, artery-to-artery embolism was the dominant stroke mechanism in extracranial atherosclerosis, both in patients with anterior (proximal internal carotid artery) and posterior (proximal vertebral artery) circulation diseases. Nevertheless, stroke mechanisms still differed in apparently similar intracranial vessels. For instance, although artery to artery embolism was the most frequent stroke mechanism in patients with middle cerebral artery disease, local branch occlusion was the most important mechanism associated with basilar artery disease. In general, artery to artery embolism was more prevalent in anterior circulation intracranial atherosclerosis, whereas local branch occlusion was more common in posterior circulation intracranial atherosclerosis. This difference may be attributable to smaller and shorter perforating vessels arising from posterior circulation arteries that may be more vulnerable to occlusion in the presence of parental artery atherothrombosis. Alternatively, because posterior circulation intracranial atherosclerosis is more closely associated with metabolic risk factors, such as hypertension and diabetes ready may be atherosclerotic and thus more vulnerable to occlusion in the presence of parental artery disease $[12,15,16]$.

\section{AIM}

The main aim of this study is to present the importance of localization of ischemic stroke in the diabetic patient, as well as the to evaluate the prognostic factors compared to acute ischemic stroke at nondiabetic patients.

\section{MATERIALS AND METHODS}

\section{Study design}

A prospective longitudinal observational study was conducted within the Clinical County Emergency Clinical Hospital of Oradea, Romania, from 1st of January 2016 until 1st of January 2019. In the study, were enrolled 340 patients, both females and males.

The inclusion criteria were as follows: age between 40 and 90 years, imaging-confirmed ischemic stroke diagnosis (CT scan). The exclusion criteria were represented by transient ischemic stroke, hemorrhagic stroke, hemorrhagic-transformed ischemic stroke, neoplastic patients, patients with autoimmune diseases, age over 90 years or under 40 years.

Upon admission, the patients enrolled in the study underwent an imaging investigation consisting of a na- 
tive CT scan. Depending on the arterial location of the ischemic stroke were divided into 3 groups MCA, PCA and $D L$ and was analyzed the localization of the stroke in the arteries, respectively the MCA, PCA and DL, correlated with age, NIHSS scale, number of days of hospitalization, survival rate and has been studied comparative the localization of the stroke in the arteries at diabetic patients and nondiabetic patients.

\section{Ethical statement}

The entire research study was conducted respecting the World Medical Association Declaration of Helsinki (Ethical Principles for Medical Research Involving Human Subjects). The study was approved by the Ethics Committee of the Clinical County Emergency Hospital of Oradea, Bihor County, Romania (decision no. 30372/06.12.2018).

\section{Methodology}

For quantification of the stroke-related neurologic deficit, it was used the National Institutes of Health Stroke Scale (NIHSS), a clinical assessment tool that estimate the acuity of stroke patients, determine the treatment, and suggest outcome prediction for the patient [17]. NIHSS is a quantitative measure of stroke-related neurologic deficit that has proven intra- and inter-rater reliability and has predictive validity for long-term stroke outcome [18-24]. Evaluation of the NIHSS in the first 24 hours after stroke onset could predict the next level of care after acute hospitalization [25].

The NIHSS is a 15-item neurologic examination stroke scale used to evaluate the effect of acute cerebral infarction on the levels of consciousness, language, neglect, visual-field loss, extraocular movement, motor strength, ataxia, dysarthria, and sensory loss. Ratings for each item are scored on a 3- to 5-point scale, with 0 as normal, and there is an allowance for untestable items. Scores range from 0 to 42 , with higher scores indicating greater severity.

Stroke severity may be stratified on the basis of $\mathrm{NI}-$ HSS scores as follows: very severe $<25$, severe $15-24$, mild to moderately severe 5-14, mild 1-5 [23,25].

Imaging investigation consisting of a native CT scan, it was done with the General Electric Optima 520 device with 16 turns (General Electric Company, USA). The images presented in the paper are selected from diabetic and non-diabetic patients enrolled in the study, having as criterion the location of ischemic stroke in the affected territories, the images being processed by the Aycan Workstation 3.12,000 version 1.20.

\section{Statistical analysis}

The database was collected in a Microsoft Excel document. The correlation analysis was processed in the MedCalc 14.1 program where correlation tests included in the program were used. The correlation coefficient $r$, which can take values between -1 and 1 was analyzed. An inversely proportional correlation between the studied parameters is defined by a value $r$ between -1 and 0 . A value of 0 , or close to it, shows the lack of any correlation, and the unilinear, directly proportional relationship is defined as a value between 0 and 1 of the correlation coefficient. For each analysis, the Gaussian distribution of the data was studied, so as to use the Pearson coefficient, if it is observed, and the Spearman coefficient if it is not observed. Results with a $p$ value less than 0.05 were validated and considered statistically significant. These correlations were represented graphically by the graphical methods available in linear regression analyzes.

The use of ROC curves was performed to determine the limit of cut-off-point values. The result of this analysis denotes the sensitivity, the specificity of these values, but also the area under the curve (AUC). The $p$ value, considered to be statistically significant, is a value below 0.05 , which is obtained by comparing the area under the analyzed curves with an area under the curve of 0.5 .

\section{RESULTS}

The predominant localization of ischemic stroke in diabetic patients was the middle cerebral artery followed by the posterior cerebral artery and the double localization compared to the group witness where the same trend is maintained. For patients where the localization was double their proportion was almost equal to a percentage of $48 \%$ of diabetic patients versus $52 \%$ of non-diabetic patients, the difference between the frequency of distribution of diabetes versus the other groups was not statistically significant $(p=0.22)$ (Figure 1). The ischemic stroke-computer tomography localization is exposed in Figure 2.

The correlation between the localization of the acute ischemic stroke studied on the three groups (middle cerebral artery, posterior cerebral artery, double localization) with age, patients have obtained the following data: there is some trend for older patients with an average value of age of 73 years to have more frequent locations of the arteries involved in the ischemic stroke (Figure 3).

The difference from patients who had an acute ischemic stroke in which it was involved only one vascular territory is almost 10 years (64.5 years for middle cerebral artery versus 64.6 years for posterior cerebral artery versus 73.57 double localization). The difference is statistically significant $p=0.02$ (table 1 ). 


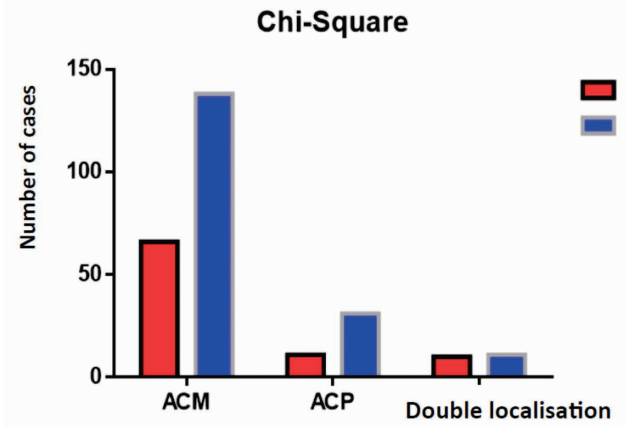

FIGURE 1. Localization of ischemic stroke between diabetic and non-diabetic patients. (MCA = middle cerebral artery, $P C A=$ posterior cerebral artery)
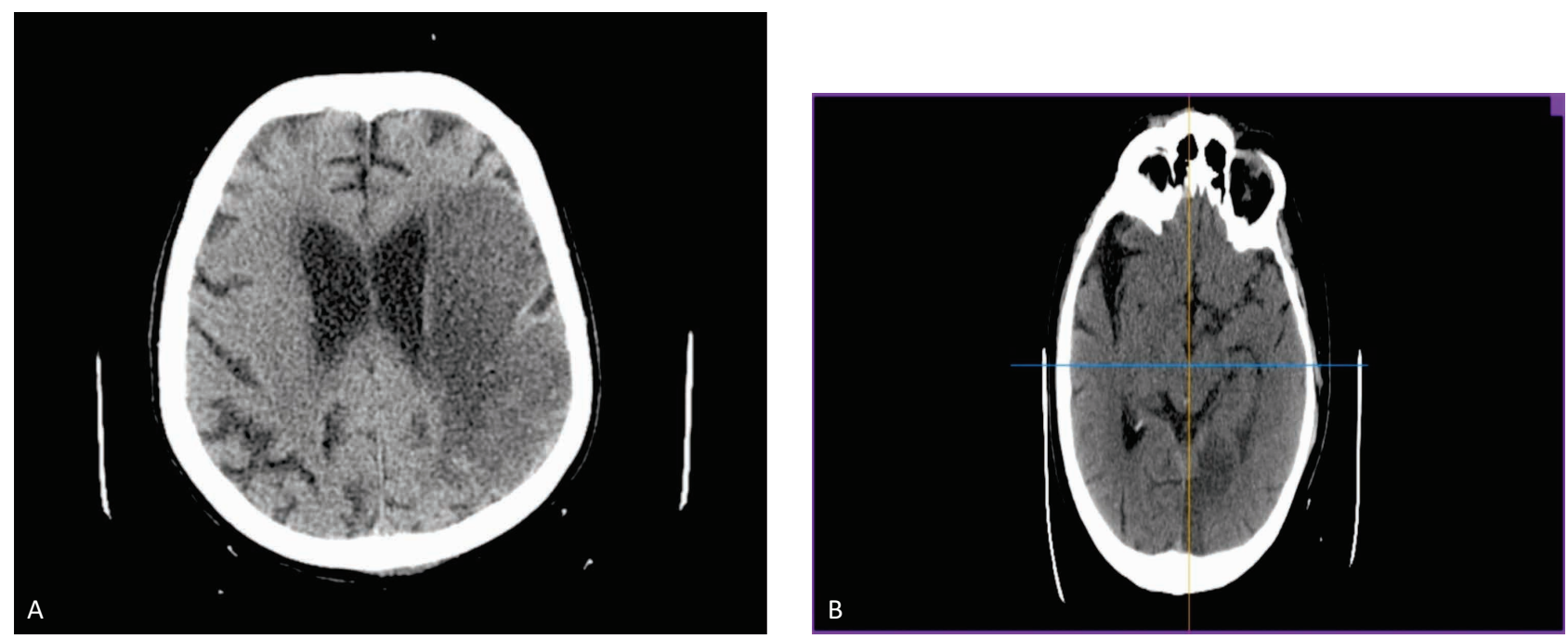

FIGURE 2. Stroke in the territory of a) the middle cerebral artery - hyper density in the territory of the middle cerebral artery, ectasic ventricular system, normally positioned, cerebral atrophy; b) the posterior cerebral artery-spontaneous hypodense beaches extending in the right cerebellar hemisphere and vermis respectively right parieto-occipital which compresses the fourth ventricle, mild supratentorial hydrocephalus

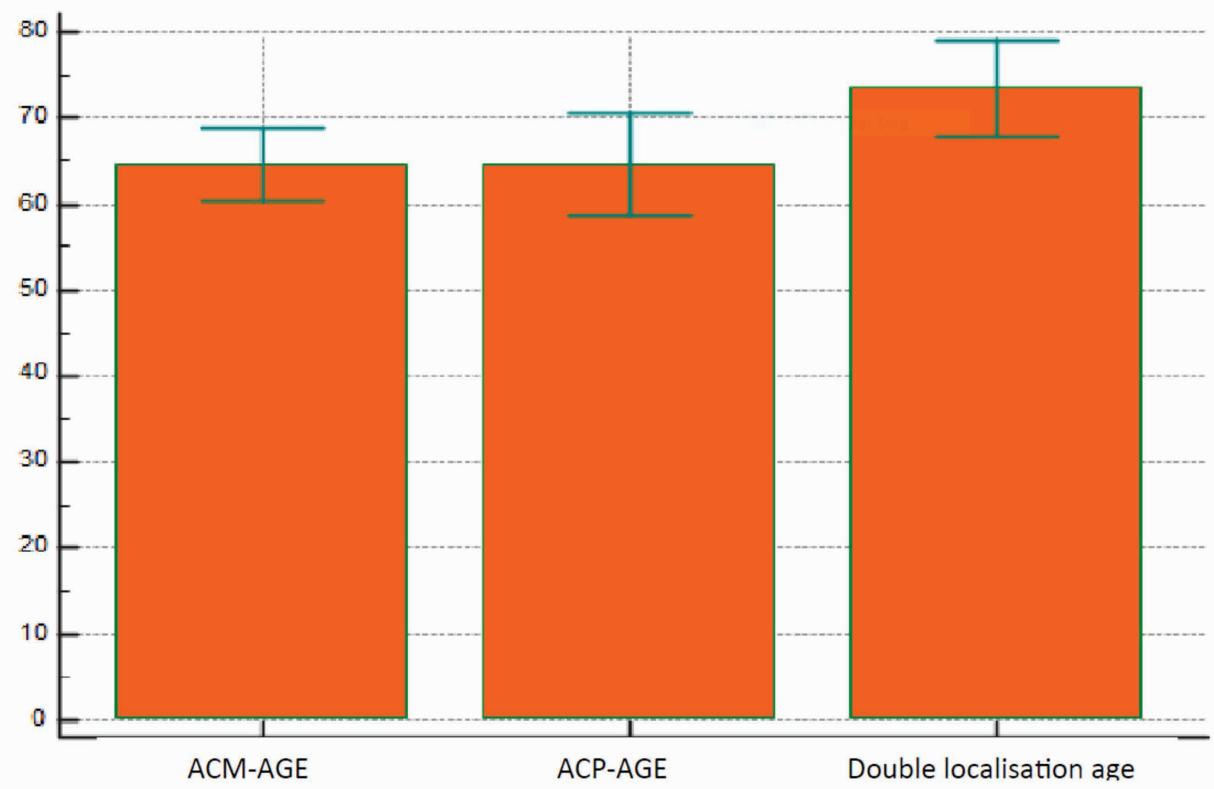

FIGURE 3. Localization of ischemic stroke and age (MCA = middle cerebral artery, $P C A=$ posterior cerebral artery) 
TABLE 1. Correlation between localization of stroke and age, $\mathrm{Cl}$ $95 \%$

\begin{tabular}{|c|c|}
\hline Vascular territory & $\begin{array}{c}\text { Average age } \\
\text { (years) }\end{array}$ \\
\hline Middle cerebral artery & $64.5(60.3832$ to 68.7596$)$ \\
\hline Posterior cerebral artery & $646(58.5794$ to 70.6587$)$ \\
\hline Double localization & $73.57(67.9991$ to 79.1437$)$ \\
\hline
\end{tabular}

Following the correlation of the NIHSS severity score with the location of ischemic strokes we obtained an NIHSS score on average of 18-19 points in case of localization on the middle cerebral artery and the posterior cerebral artery, the double location of an affect- ed area greatly increases the score severity to an average of 24 points (Figure 4).

The difference is strongly statistically significant between both averages and linear trend analysis quadratic $(p<0.0001)$, as it is shown in Table 2.

TABLE 2. Correlation between localization of ischemic stroke and NIHSS scale, $\mathrm{Cl} 95 \%$

\begin{tabular}{|c|c|}
\hline Vascular territory & NIHSS points \\
\hline Middle cerebral artery & 18.9 (17.4660 to 20.3435$)$ \\
\hline Posterior cerebral artery & $18.5(17.3942$ to 20.3201$)$ \\
\hline Double localization & 24 (23.2073 to 25.554$)$ \\
\hline
\end{tabular}

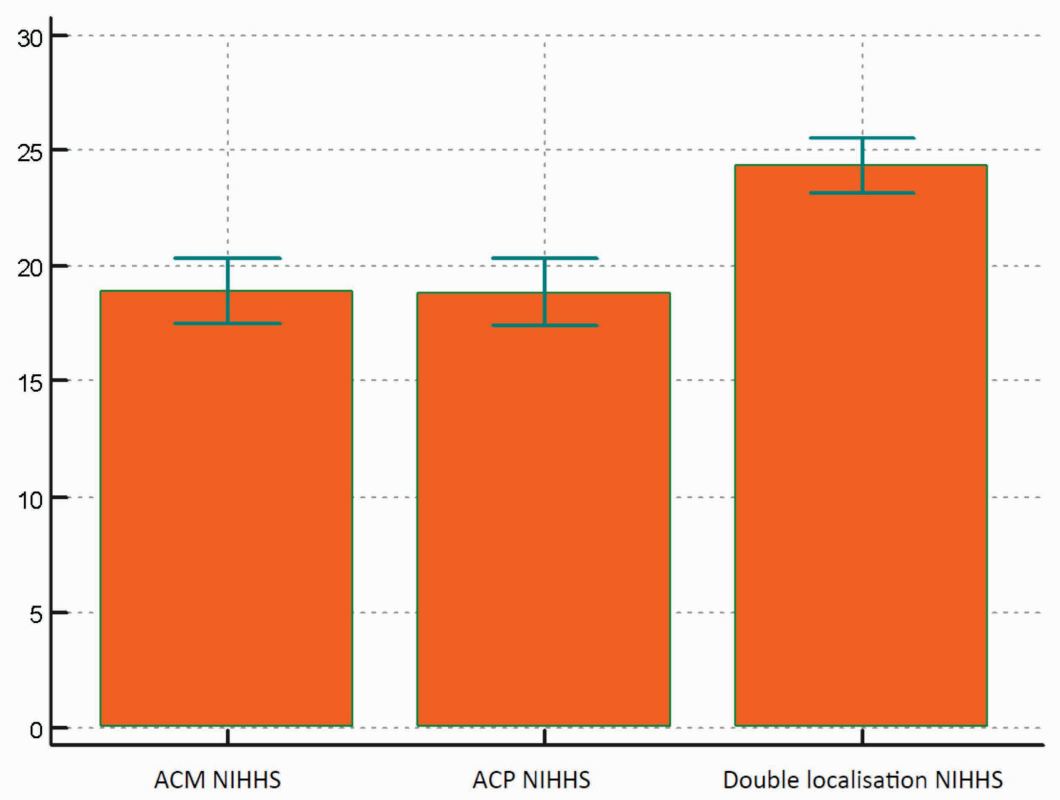

FIGURE 4. Localization of ischemic stroke and NIHSS (MCA - middle cerebral artery, PCA - posterior cerebral artery)

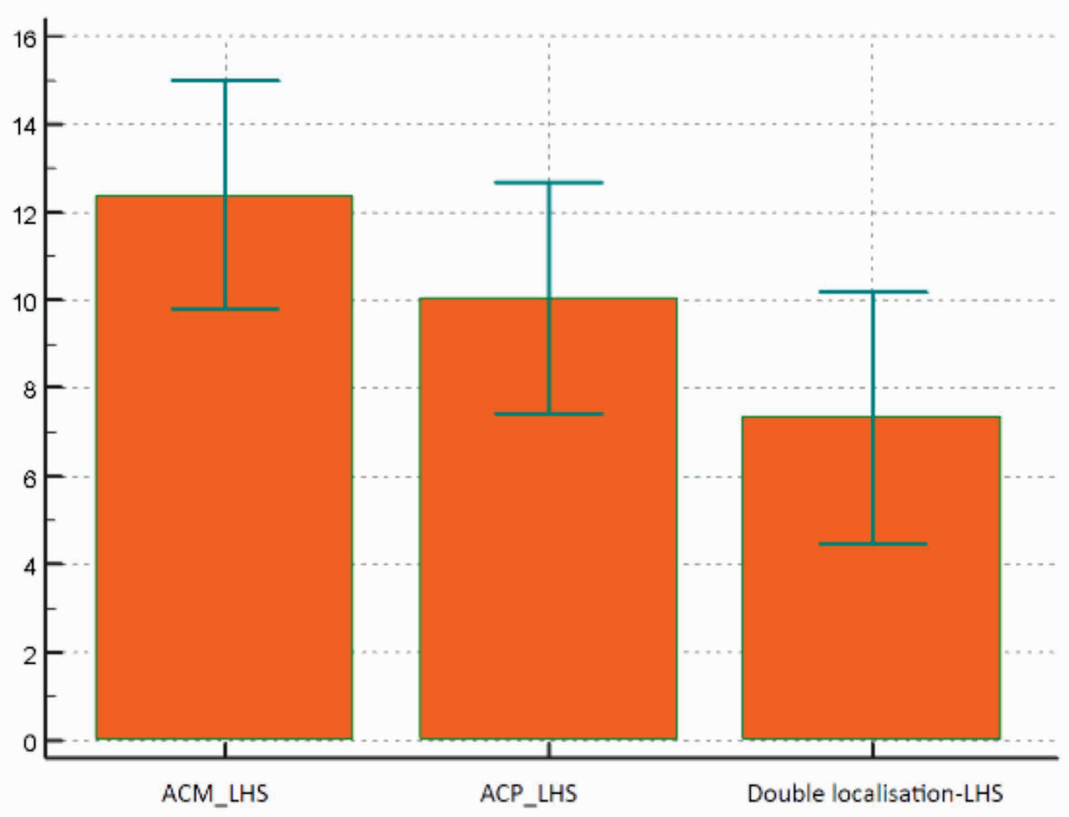

FIGURE 5. Localization of ischemic stroke and number of hospitalization days 
Patients with acute ischemic stroke in the territory of the median cerebral artery have the longest average hospitalization being ( $n=12$ days) followed by those whose location was the posterior cerebral artery ( $n=10$ days). The shortest days of hospitalization are the patients with double location with an average ( $n=7$ days), $p<0.0117$ (Figure 5).

The difference from patients who had an acute ischemic stroke in which involved only one vascular territory is like middle cerebral artery with 12.38 days of length of hospitalization days, posterior cerebral artery with 10.04 days of length of hospitalization days and double localization with 7.33 days, $p<0.0017$ (Table 3).

TABLE 3. Correlation between localization of ischemic stroke and number of hospitalization days, Cl 95\%

\begin{tabular}{|c|c|}
\hline Vascular territory & $\begin{array}{c}\text { Average days of } \\
\text { hospitalization }\end{array}$ \\
\hline Middle cerebral artery & $12.38(9.7801$ to 14.9818$)$ \\
\hline Posterior cerebral artery & $10.04(7.4111$ to 12.6841$)$ \\
\hline Double localization & $7.33(4.4822$ to 10.1845$)$ \\
\hline
\end{tabular}

The data obtained from the Kaplan-Meier analysis on the survival of patients (divided by the vascular territory involved), provided an expected result. Patients with vascular accident in the territory of the median cerebral artery have the highest survival rate, with an average of 22 days, followed by those whose territory was the posterior cerebral artery, with an average of 19 days, and, regarding the double location, the lowest survival rate was obtained with an average of 4 days (Figure 5).

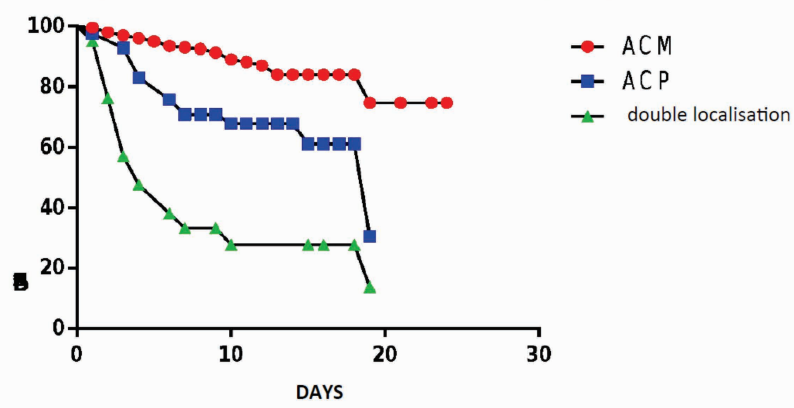

FIGURE 6. Survival according to localization of ischemic stroke

This difference is statistically significant $(p<0.0001)$ and systematic time goes on, as can be seen in the Table 4.

TABLE 4. Survival proportion according to localization of ischemic stroke

\begin{tabular}{|c|c|c|c|}
\hline Days & MCA & PCA & Double localization \\
\hline 0.000 & 100.000 & 100.000 & 100.000 \\
\hline 1.000 & 99.5098 & 97.61905 & 95.2381 \\
\hline 2.000 & 98.03194 & - & 76.19048 \\
\hline
\end{tabular}

\begin{tabular}{|c|c|c|c|}
\hline Days & MCA & PCA & Double localization \\
\hline 3.000 & 97.04669 & 92.85714 & 57.14286 \\
\hline 4.000 & 96.06145 & 83.08271 & 47.61905 \\
\hline 5.000 & 95.0762 & - & - \\
\hline 6.000 & 93.58286 & 75.75188 & 38.09524 \\
\hline 7.000 & 93.07425 & 70.86466 & 33.33333 \\
\hline 8.000 & 92.51692 & 70.86466 & - \\
\hline 9.000 & 91.28336 & 70.86466 & 33.33333 \\
\hline 10.000 & 89.00128 & 67.91196 & 27.77778 \\
\hline 11.000 & 88.08374 & 67.91196 & - \\
\hline 12.000 & 87.03513 & 67.91196 & - \\
\hline 13.000 & 84.03391 & 67.91196 & - \\
\hline 14.000 & 84.03391 & 67.91196 & - \\
\hline 15.000 & 84.03391 & 61.12077 & 27.77778 \\
\hline 16.000 & 84.03391 & 61.12077 & 27.77778 \\
\hline 17.000 & 84.03391 & 61.12077 & - \\
\hline 18.000 & 84.03391 & 61.12077 & 27.77778 \\
\hline 19.000 & 74.69681 & 30.56038 & 13.88889 \\
\hline 21.000 & 74.69681 & & \\
\hline 23.000 & 74.69681 & & \\
\hline 24.000 & 74.69681 & & \\
\hline
\end{tabular}

\section{DISCUSSIONS}

Diabetes patients have a higher risk of developing complications in hospitalization, with greater discharge disability, higher incidence of recurrent stroke, and increased mortality at 90 days from onset of ischemic stroke [26]. Considering the data obtained in this study, diabetes is not an independent risk factor for a particular localization in acute ischemic stroke. Advanced age was found also as another risk factor, correlated with mortality and disability [27,28-31].

The results of Zafar study did not show any statistically significant differences in age and gender distribution between the 2 groups [32]. No significant age difference was identified between the two groups in other studies as well. $[33,34]$. In the present research, the difference between the frequency of distribution of diabetes vs. the other group was not statistically significant ( $p=0.22)$.

In one study [35] diabetics were relatively older than non-diabetics and in a recent multinational study diabetes mellitus was independently associated with a slightly younger age [36]. Our data revealed that the difference from patients who has an acute ischemic stroke (in which it was involved only one vascular territory) is almost 10 years; there is some trend for older patients with an average value of age of 73 years to have more frequent locations of the arteries involved in the ischemic stroke ( $p=0.02$ ) to an average of 24, the difference being strong statistically significant $p<0.0001$.

Microangiopathic category and lacunar infarction were more common in the diabetic group than non-di- 
abetic as mentioned in other prospective studies describing the patterns of stroke in diabetic patients $[34,35,37]$. A large prospective European multicenter study conducted by Megherbi et al. [34] characterizing stroke pattern in diabetic patients found that the frequency of intracerebral hemorrhage was lower, the rate of lacunar infarction was higher, and recovery was worse in diabetic patients.

Higher frequencies of lacunar infarction can be explained by the hypothesis that diabetes mellitus can lead to small vessel arteriolopathy in various organs of the body, especially in the retina, kidneys and brain [38]. Diabetes is not only a risk factor for ischemic stroke but can lead to more insidious brain damage represented by lacunar infarction and hence increases the risk of dementia as well [39].

The sub-types and topography of ischaemic stroke are presumed to differ between diabetic and non diabetic individuals according to the type of angiopathy induced by diabetes mellitus. Lacunar (small, less than $15 \mathrm{~mm}$ in diameter infarction, cyst like, frequently multiple) is the typical type of stroke in diabetic subjects [40]. Lacunar infarcts are typically found in the distribution of deep perforating arteries [41].

Zafar study [33] found significant differences in subtypes of ischaemic stroke in diabetics and non-diabetics. Cortical infarct was the commonest subtype in both groups and subcortical infarct were more frequent in diabetics than non-diabetics. As far as the aetiology of ischaemic stroke is concerned, large artery disease was more common than small vessel disease in diabetic group. Similar result was described in one more study [35].

In Bamford et al. study diabetic group, the distribution of the pathological subtypes of stroke [42] was slightly different, with more posterior circulation infarct and lacunar infarct syndromes. The Arboix et al. study observe more lacunar infarct syndromes in diabetic patients has not been reported in other study [43], which raises the problem of biases induced by small series, the definition of diabetes, and other methodological aspects $[6,43]$.

The type and topography of diabetes-related cerebral infarction are believed to differ from brain infarcts in nondiabetic individuals [44]. Diabetes has been thought to be a risk factor for small and lacunar infarcts $[45,46]$. The study of Jørgensen et al. could not confirm this association. They found no significant differences between the groups regarding infarct size, site, and initial stroke severity. The symptomatic infarct seems therefore to be similar in patients with and without diabetes [6].

The study of Karapanayiotides et al. [35] revealed differences in the topography of ischemic stroke between patients with diabetes mellitus and non-diabetic patients: subcortical infarcts were more frequent in diabetes mellitus, whereas complete middle cerebral artery territory infarcts were less frequent posterior cerebral infarction was higher in patients with diabetes mellitus in accordance with an MRI study [47], which suggested a greater vulnerability to posterior circulation ischemia in diabetics.

The NIH Stroke Scale (NIHSS) is a neurologic severity scale that is valid, reliable, and reproducible [48]; it is commonly used in many clinical trials dealing with medical therapy for acute stroke [49]. Baseline NIHSS scores on admission are associated with chronic functional outcome [49], hospital disposition after stroke[50], infarct volume, and angiographic findings [51]. In the trial of ORG 10172 in Acute Stroke Treatment (TOAST), the baseline NIHSS score was lower in patients with posterior circulation (PC) stroke than in patients with anterior circulation (AC) stroke [52].

Fink et al. [53] reported a significant correlation between diffusion-weighted MR imaging lesion volume and NIHSS score. Several studies examined relationships between initial NIHSS score and vascular imaging techniques such as CT angiography [54], and MR angiography [55], reporting that a higher NIHSS score was associated with more severe vascular lesions in patients with acute stroke. However, vascular imaging methods have limitations in clearly displaying occlusion or stenosis of the main stem and branches of the middle cerebral artery (MCA) and anterior cerebral artery (ACA). Relationships between NIHSS score and site of arterial occlusion during the hyperacute phase of stroke, therefore, have yet to be accurately determined. From the data of this study, the NIHSS correlation with the location of ischemic strokes, it was obtained an average NIHSS score of 18-19, in the case of localization on the middle cerebral artery or on the posterior cerebral artery, the double location of an affected area greatly increasing the score severity.

Some studies have reported no significant differences in NIHSS scores between patients with middle cerebral artery trunk occlusion and internal carotid artery/middle cerebral artery tandem occlusion, a result that is compatible with the present results [56]. When the internal carotid artery is occluded, the severity of neurologic deficit is contingent on collateral blood flow through the anterior communicating or leptomeningeal arteries from the anterior cerebral artery or posterior cerebral artery [56].

This NIHSS score at baseline was indeed lower among posterior circulation patients, although this may in part be an artifact of the elements of the scale, which are more highly weighted towards anterior circulation deficits, e.g. aphasia, neglect and motor function. Thus, the NIHSS does not fully 'capture' the spectrum of posterior circulation-related deficits [57]. The 
NIHSS has been used as an outcome in many randomized trials of stroke. A difference of one point in the total NIHSS score (e.g. between mild versus moderate limb weakness) is associated with greater length of stay, increased mortality, and increased costs of care [58-60].

In study of Chang for patients with mild or moderate neurological impairments 1 point increase of NIHSS scale correspond to an increase in length of stay, also when patient had severe neurological impairment correspond to a decrease in hospitalization [61].

The decreased length of hospitalization in patients with more severe stroke was largely related to the mortality rate, fact confirmed in the present research by the less days of hospitalization of the patients with double location (with an average ( $n=7$ days)), the most probably in the context of stroke severity and early death $(p<0.0117)$.

Stroke subtype was also a strong predictor of length of hospital stay, with small-vessel occlusion stroke associated with an approximately 1.5-day shorter length of hospital stay than the other subtypes ( $p$ 0.001) [61].

Initial stroke severity, but not age or comorbidity, was shown to be one of the significant predictors of length of hospital stay, we may postulate the hypothesis that initially reducing stroke severity in first-ever ischemic stroke patients with mild or moderately severe stroke might be a wiser way to reduce length of hospital stay after acute care hospitalization [61].

The total anterior cerebral infarction. group had a higher mortality, longer length of stay, more severe disability, and a higher incidence of complications than the other 3 subgroups (partial anterior cerebral infarction, posterior cerebral infarction, and lacunar cerebral infarction) who were similar at the different time points apart from rate of stroke recurrence within the first 6 months, which was significantly higher in the posterior cerebral infarction group compared to the other groups [62]. In our study, Kaplan-Meier analysis showed that patients with vascular accident in the territory of the middle cerebral artery have the highest survival rate, with an average of 22 days, followed by those whose territory was the posterior cerebral artery (with an average of 19 days); regarding the double location, the lowest survival rate was obtained with an average of 4 days, difference is statistically significant ( $p<0.0001)$.

The study by Gattringer et al. showed that the location of the cerebral infarction in the posterior territory has a higher mortality rate than the anterior territory, most likely due to the mass effect exerted on the brainstem [60].

In the literature is no consensus regarding progression of stroke in terms of lesion topography, than posterior circulation infarctions were found to be significantly more frequent in the patients with neurological worsening. Similar findings were reported in other studies of literature $[63,64]$.

The initial severity of neurological deficit was considered as an independent risk factor for outcomes in most studies [27,28-31].

DeGraba et al. found no difference in lesion topography between the patients with or without neurological worsening [65], while others reported frequently progression in the anterior circulation infarcts $[66,67]$. A lower rate of cardioembolic infarcts in the posterior circulation compared with anterior circulation might explain this finding [68]. However, infarct topography was found to be an independent factor for neurological progression in this study.

Diabetes is an independent risk factor of death from stroke. Tuomilehto et al. [69] calculated that $16 \%$ of all stroke mortality in men and $33 \%$ in women could be directly attributed to diabetes. However, one local study could not show much difference in the outcome in the diabetics versus non-diabetics [70]. One large prospective European multicentre study [34] calculated that stroke in diabetic patients was different from stroke in non-diabetics from several perspectives.

The study of Sumer et al. shows that progressing stroke severely affects the prognosis of patients, increases mortality more than four times and leads to poor functional outcome scores. The frequency of deterioration in acute ischemic stroke depends on infarct topography and stroke subtype [71].

However, infarct progression is a grave condition that limits alternatives and leads medical staff to make urgent decisions, thus preventing standard protocols. Small sample size also causes restrictions. Further studies with larger patient populations are needed to resolve these problems.

\section{CONCLUSIONS}

There is no statistically significant difference between diabetic vs. non-diabetic patients regarding the localization correlated with DM, the double location being statistically insignificant between the two batches. Age-related location is statistically significant due to the unique location difference or double, the double location having a higher frequency in elderly patients. In case of correlation of localization with NIHSS severity score, double location of a territory affected significantly increases the severity score, the difference being strongly statistical. Localization correlation with number of hospitalization days with poor prognosis for patients with double location compared to the single-location group with a more favorable prognosis. The survival rate in patients with double localization is low compared to patients with unique vascular territory. 


\section{REFERENCES}

1. Jauch EC, Saver JL, Adams HP Jr, Bruno A, Connors JJ, Demaerschalk BM, et al.; American Heart Association Stroke Council; Council on Cardiovascular Nursing; Council on Peripheral Vascular Disease; Council on Clinical Cardiology. Guidelines for the early management of patients with acute ischemic stroke: a guideline for healthcare professionals from the American Heart Association/American Stroke Association. Stroke. 2013 Mar;44(3):870-947.

2. O'Donnell MJ, Xavier D, Liu L, Zhang H, Chin SL, Rao-Melacini P, et al.; INTERSTROKE investigators. Risk factors for ischaemic and intracerebral haemorrhagic stroke in 22 countries (the INTERSTROKE study): a case-control study. Lancet. 2010 Jul 10;376(9735):112-23.

3. Lukovits TG, Mazzone TM, Gorelick TM. Diabetes mellitus and cerebrovascular disease. Neuroepidemiology. 1999; 18(1):1-14

4. Arboix A, Morcillo C, García-Eroles L, Oliveres M, Massons J, Targa C. Different vascular risk factor profiles in ischemic stroke subtypes: a study from the "Sagrat Cor Hospital of Barcelona Stroke Registry". Acta Neurol Scand. 2000 Oct;102(4):264-70.

5. Olsson T, Viitanen M, Asplund K, Eriksson S, Hägg E. Prognosis after stroke in diabetic patients. A controlled prospective study. Diabetologia. 1990 Apr;33(4):244-9.

6. Jørgensen $\mathrm{H}$, Nakayama H, Raaschou HO, Olsen TS. Stroke in patients with diabetes. The Copenhagen Stroke Study. Stroke. 1994 Oct;25(10):1977-84.

7. Oppenheimer SM, Hoffbrand BI, Oswald GA, Yudkin JS. Diabetes mellitus and early mortality from stroke. Br Med J (Clin Res Ed). 1985 Oct 12;291(6501):1014-5.

8. Kulesh SD, Filina NA, Frantava NM, Zhytko NL, Kastsinevich TM, Kliatskova LA, Shumskas MS, Hilz MJ, Schwab S, Kolominsky-Rabas PL. Incidence and case-fatality of stroke on the East border of the European union: The Grodno Stroke Study. Stroke. 2010 Dec;41(12):2726-30.

9. Truelsen T, Piechowski-Jóźwiak B, Bonita R, Mathers C, Bogousslavsky J, Boysen G. Stroke incidence and prevalence in Europe: a review of available data. Eur $\mathrm{J}$ Neurol. 2006 Jun;13(6):581-98.

10. Béjot Y, Bailly H, Durier J, Giroud M. Epidemiology of stroke in Europe and trends for the 21st century. Presse Med. 2016 Dec;45(12 Pt 2):e391-e398.

11. Jordan, Danny \& Islamiyah, Wardah \& Prayitno, Jongky. Profile of type 2 diabetes mellitus in acute thrombotic stroke. MNJ 2019 (Malang Neurology Journal). 5. 80-85.

12. Subramanian G, Silva J, Silver FL, Fang J, Kapral MK, Oczkowski W, Gould L, O'Donnell MJ; Investigators of the Registry of the Canadian Stroke Network. Risk factors for posterior compared to anterior ischemic stroke: an observational study of the Registry of the Canadian Stroke
Network. Neuroepidemiology. 2009; 33(1):12-6.

13. Shinya $Y$, Miyawaki S, Imai $H$, Hongo $H$, Ono $\mathrm{H}$, Takenobu A, Nakatomi H, Teraoka A, Saito N. Genetic Analysis of Ring Finger Protein 213 (RNF213) c. 14576G>A in Intracranial Atherosclerosis of the Anterior and Posterior Circulations. J Stroke Cerebrovasc Dis. 2017 Nov;26(11):26382644.

14. Pop NO, Zaha DC, Pantiș C, Mekeres F. Clinicopathological evaluation of Moyamoya disease. Case report and review of literature. Romanian Journal of Military Medicine 2020;123(2):102.

15. Subramanian G, Silva J, Silver FL, Fang J, Kapral MK, Oczkowski W, Gould L, O'Donnell MJ; Investigators of the Registry of the Canadian Stroke Network. Risk factors for posterior compared to anterior ischemic stroke: an observational study of the Registry of the Canadian Stroke Network. Neuroepidemiology. 2009; 33(1):12-6.

16. SPILKER Judith, Kongable G, Barch $C$, Braimah J, Brattina P, Daley S, Donnarumma R, Rapp K, Sailor S. Using the $\mathrm{NIH}$ Stroke Scale to assess stroke patients. Journal of Neuroscience Nursing. 1997;29(6):384-393.

17. Kotila M, Waltimo O, Niemi ML, Laaksonen $R$, Lempinen $M$. The profile of recovery from stroke and factors influencing outcome. Stroke. 1984 Nov-Dec;15(6):1039-44.

18. Brott T, Marler JR, Olinger CP, Adams HP Jr, Tomsick T, Barsan WG, Biller J, Eberle R, Hertzberg V, Walker M. Measurements of acute cerebral infarction: lesion size by computed tomography. Stroke. 1989 Jul;20(7):871-5.

19. Lyden P, Brott T, Tilley B, Welch KM, Mascha EJ, Levine S, Haley EC, Grotta J, Marler J. Improved reliability of the NIH Stroke Scale using video training. NINDS TPA Stroke Study Group. Stroke. 1994 Nov; 25(11):2220-6.

20. Goldstein LB, Samsa GP. Reliability of the National Institutes of Health Stroke Scale. Extension to non-neurologists in the context of a clinical trial. Stroke. 1997 Feb;28(2):307-10.

21. Muir KW, Weir CJ, Murray GD, Povey C, Lees KR. Comparison of neurological scales and scoring systems for acute stroke prognosis. Stroke. 1996 Oct;27(10):1817-20.

22. Schlegel D, Kolb SJ, Luciano JM, Tovar JM, Cucchiara BL, Liebeskind DS, Kasner SE. Utility of the NIH Stroke Scale as a predictor of hospital disposition. Stroke. 2003 Jan;34(1):134-7.

23. Allen CM. Predicting the outcome of acute stroke: a prognostic score. J Neurol Neurosurg Psychiatry. 1984 May; 47(5):475-80.

24. Fiorelli M, Alpérovitch A, Argentino $C$, Sacchetti ML, Toni D, Sette G, Cavalletti C, Gori MC, Fieschi C. Prediction of long-term outcome in the early hours following acute ischemic stroke. Italian Acute Stroke Study Group. Arch Neurol. 1995 Mar;52(3):250-5.

25. Generalized efficacy of t-PA for acute stroke. Subgroup analysis of the NINDS t-PA Stroke Trial. Stroke. 1997 Nov;28(11):2119-25.

26. Akhtar N, Kamran S, Singh R, Malik RA, Deleu D, Bourke PJ, Joseph S, et al. The Impact of Diabetes on Outcomes After Acute Ischemic Stroke: A Prospective Observational Study. J Stroke Cerebrovasc Dis. 2019 Mar;28(3):619-626.

27. Hénon H, Godefroy O, Leys D, MounierVehier F, Lucas C, Rondepierre P, Duhamel A, Pruvo JP. Early predictors of death and disability after acute cerebral ischemic event. Stroke. 1995 Mar;26(3):392-8.

28. Kotila M, Waltimo O, Niemi ML, Laaksonen $\mathrm{R}$, Lempinen $\mathrm{M}$. The profile of recovery from stroke and factors influencing outcome. Stroke. 1984 Nov-Dec;15(6):1039-44.

29. Allen CM. Predicting the outcome of acute stroke: a prognostic score. J Neurol Neurosurg Psychiatry. 1984 May; 47(5):475-80.

30. Sweileh WM, Sawalha AF, Al-Aqad SM, Zyoud SH, Al-Jabi SW. Predictors of in-Hospital Mortality after Acute Stroke: Impact of Gender. Int J Clin Exp Med. 2009;2(1):41-7.

31. National Institute of Neurological Disorders and Stroke rt-PA Stroke Study Group. Tissue plasminogen activator for acute ischemic stroke. N Engl J Med. 1995 Dec 14;333(24):1581-7.

32. Zafar A. Diabetic patients are at a higher risk of lacunar infarction and dyslipidemia: results of a comparative pilot study from King Fahad Hospital of the University, Saudi Arabia. Neurosciences (Riyadh). 2017 Jan;22(1):20-24.

33. Zafar A, Shahid SK, Siddiqui M, Khan FS. Pattern of stroke in type 2 diabetic subjects versus non diabetic subjects. J Ayub Med Coll Abbottabad. 2007 Oct-Dec;19(4):64-7.

34. Megherbi SE, Milan C, Minier D, Couvreur G, Osseby GV, Tilling K, Di Carlo A, Inzitari D, Wolfe CD, Moreau T, Giroud M; European BIOMED Study of Stroke Care Group. Association between diabetes and stroke subtype on survival and functional outcome 3 months after stroke: data from the European BIOMED Stroke Project. Stroke. 2003 Mar;34(3):688-94.

35. Karapanayiotides T, Piechowski-Jozwiak B, van Melle G, Bogousslavsky J, Devuyst G. Stroke patterns, etiology, and prognosis in patients with diabetes mellitus. Neurology. 2004 May 11;62(9):1558-62.

36. Palacio S, McClure LA, Benavente OR, Bazan C 3rd, Pergola P, Hart RG. Lacunar strokes in patients with diabetes mellitus: risk factors, infarct location, and prognosis: the secondary prevention of small subcortical strokes study. Stroke. 2014 Sep;45(9):2689-94.

37. Pinto A, Tuttolomondo A, Di Raimondo D, Di Sciacca R, Fernandez P, Di Gati M, Arnao V, Licata $\mathrm{G}$. A case control study between 
diabetic and non-diabetic subjects with ischemic stroke. Int Angiol. 2007

Mar;26(1):26-32.

38. Kissela BM, Khoury J, Kleindorfer D, Woo D Schneider A, Alwell K, Miller R, Ewing I, Moomaw CJ, Szaflarski JP, Gebel J, Shukla $\mathrm{R}$, Broderick JP. Epidemiology of ischemic stroke in patients with diabetes: the greater Cincinnati/Northern Kentucky Stroke Study. Diabetes Care. 2005 Feb;28(2):355-9.

39. Tuttolomondo A, Maida C, Maugeri R, lacopino G, Pinto A. Relationship between Diabetes and Ischemic Stroke: Analysis of DiabetesRelated Risk Factors for Stroke and of Specific Patterns of Stroke Associated with Diabetes Mellitus. J Diabetes Metab. 2015;6(5):544-60.

40. Ghika J, Bogousslavsky J, Regli F. Infarcts in the territory of the deep perforators from the carotid system. Neurology. 1989 Apr;39(4):507-12.

41. Mohr JP, Caplan LR, Melski JW, Goldstein RJ, Duncan GW, Kistler JP, Pessin MS, Bleich HL. The Harvard Cooperative Stroke Registry: a prospective registry. Neurology. 1978 Aug;28(8):754-62.

42. Bamford J, Sandercock P, Dennis M, Burn J Warlow C. Classification and natural history of clinically identifiable subtypes of cerebral infarction. Lancet. 1991 Jun 22;337(8756):1521-6.

43. Arboix A, Cendrós V, Besa M, García-Eroles L, Oliveres M, Targa C, Balcells M, Comes $\mathrm{E}$, Massons J. Trends in risk factors, stroke subtypes and outcome. Nineteen-year data from the Sagrat Cor Hospital of Barcelona stroke registry. Cerebrovasc Dis. 2008;26(5):509-16

44. Helgason CM. Blood glucose and stroke. Stroke. 1988 Aug;19(8):1049-53

45. Hirsch CH, Sommers L, Olsen A, Mullen L, Winograd $\mathrm{CH}$. The natural history of functional morbidity in hospitalized older patients. J Am Geriatr Soc. 1990 Dec;38(12):1296-303.

46. Lithner F, Asplund K, Eriksson S, Hagg E, Strand T, Wester PO. Clinical characteristics in diabetic stroke patients. Diabete \& Metabolisme. 1988 Jan-Feb;14(1):15-19.

47. Iwase M, Yamamoto M, Yoshinari M, Ibayashi S, Fujishima M. Stroke topography in diabetic and nondiabetic patients by magnetic resonance imaging. Diabetes Res Clin Pract. 1998 Nov;42(2):109-16.

48. Kasner SE. Clinical interpretation and use of stroke scales. Lancet Neurol. 2006 Jul;5(7):603-12.

49. Adams HP Jr, Davis PH, Leira EC, Chang $\mathrm{KC}$, Bendixen BH, Clarke WR, Woolson RF, Hansen MD. Baseline NIH Stroke Scale score strongly predicts outcome after stroke: A report of the Trial of Org 10172 in Acute
Stroke Treatment (TOAST). Neurology. 1999 Jul 13;53(1):126-31.

50. Schlegel DJ, Tanne D, Demchuk AM, Levine SR, Kasner SE; Multicenter rt-PA Stroke Survey Group. Prediction of hospital disposition after thrombolysis for acute ischemic stroke using the National Institutes of Health Stroke Scale. Arch Neurol. 2004 Jul;61(7):1061-4.

51. Fischer U, Arnold M, Nedeltchev K, Brekenfeld C, Ballinari P, Remonda L, Schroth G, Mattle HP. NIHSS score and arteriographic findings in acute ischemic stroke. Stroke. 2005 Oct;36(10):2121-5.

52. Libman RB, Kwiatkowski TG, Hansen MD, Clarke WR, Woolson RF, Adams HP. Differences between anterior and posterior circulation stroke in TOAST. Cerebrovasc Dis. 2001;11(4):311-6.

53. Fink JN, Selim MH, Kumar S, Silver B Linfante I, Caplan LR, Schlaug G. Is the association of National Institutes of Health Stroke Scale scores and acute magnetic resonance imaging stroke volume equal for patients with right- and left-hemisphere ischemic stroke? Stroke. 2002 Apr;33(4):954-8.

54. Verro P, Tanenbaum LN, Borden NM, Sen S, Eshkar N. CT angiography in acute ischemic stroke: preliminary results. Stroke. 2002 Jan;33(1):276-8

55. Derex L, Nighoghossian N, Hermier M, Adeleine P, Froment JC, Trouillas P. Early detection of cerebral arterial occlusion on magnetic resonance angiography: predictive value of the baseline NIHSS score and impact on neurological outcome. Cerebrovasc Dis. 2002;13(4):225-9.

56. Linfante I, Llinas RH, Selim M, Chaves C, Kumar S, Parker RA, Caplan LR, Schlaug G. Clinical and vascular outcome in internal carotid artery versus middle cerebral artery occlusions after intravenous tissue plasminogen activator. Stroke. 2002 Aug;33(8):2066-71.

57. Pinto AN, Melo TP, Lourenço ME, Leandro MJ, Brázio A, Carvalho L, Franco AS, Ferro JM. Can a clinical classification of stroke predict complications and treatments during hospitalization? Cerebrovasc Dis. 1998 Jul-Aug;8(4):204-9.

58. Schlegel D, Kolb SJ, Luciano JM, Tovar JM, Cucchiara BL, Liebeskind DS, Kasner SE. Utility of the NIH Stroke Scale as a predictor of hospital disposition. Stroke. 2003 Jan;34(1):134-7

59. Johnston KC, Connors AF Jr, Wagner DP, Knaus WA, Wang XQ, E. Clarke HaleyJr; for the Randomized Trial of Tirilazad Mesylate in Acute Stroke (RANTTAS) Investigators. A Predictive Risk Model for Outcomes of Ischemic Stroke. Stroke. 2000;31:448-455.
60. Gattringer T, Posekany A, Niederkorn K, Knoflach M, Poltrum B, Mutzenbach S, Haring HP, et al.; Austrian Stroke Unit Registry Collaborators. Predicting Early Mortality of Acute Ischemic Stroke. Stroke. 2019 Feb;50(2):349-356.

61. Chang KC, Tseng MC, Hsu-Huei Weng HH, Lin YH, Liou CW, Tan TY. Prediction of Length of Stay of First-Ever Ischemic Stroke. Stroke. 2002;33:2670-2674.

62. Pittock SJ, Meldrum D, Hardima, O, Thornton J, Brennan P, Moroney JT. The Oxfordshire Community Stroke Project Classification: Correlation with imaging associated complications, and prediction of outcome in acute ischemic stroke. Journal of Stroke and Cerebrovascular Diseases 2003;12(1):1-7.

63. Yamamoto $\mathrm{H}$, Bogousslavsky J, van Melle G. Different Predictors of Neurological Worsening in Different Causes of Stroke. Arch Neurol. 1998;55(4):481-486.

64. Jones HR Jr, Millikan CH, Sandok BA. Temporal profile (clinical course) of acute vertebrobasilar system cerebral infarction. Stroke. 1980;11:173-177

65. DeGraba TJ, Hallenbeck JM, Pettigrew KD, Dutka AJ, Kelly BJ. Progression in acute stroke: value of the initial $\mathrm{NIH}$ stroke scale score on patient stratification in future trials. Stroke. 1999 Jun;30(6):1208-12.

66. Dávalos A, Cendra E, Teruel J, Martinez M, Genís D. Deteriorating ischemic stroke: risk factors and prognosis. Neurology. 1990 Dec;40(12):1865-9.

67. Tei H, Uchiyama S, Ohara K, Kobayashi M, Uchiyama Y, Fukuzawa M. Deteriorating ischemic stroke in 4 clinical categories classified by the Oxfordshire Community Stroke Project. Stroke. 2000 Sep;31(9):2049-54

68. Lee BI, Nam HS, Heo JH, Kim DI; Yonse Stroke Team. Yonsei Stroke Registry. Analysis of 1,000 patients with acute cerebral infarctions. Cerebrovasc Dis. 2001;12(3):145-51.

69. Tuomilehto J, Rastenyte D, Jousilahti P, Sart C, Vartiainen E. Diabetes mellitus as a risk factor for death from stroke. Prospective study of the middle-aged Finnish population. Stroke. 1996 Feb;27(2):210-5.

70. Basir F, Ali S, Aziz H. Stroke recovery and outcome in diabetes. Journal-College Of Physicians And Surgeons Of Pakistan 2001;11:736-738

71. Sumer M, Ozdemir I, Erturk O. Progression in acute ischemic stroke: frequency, risk factors and prognosis. J Clin Neurosci. 2003 Mar;10(2):177-80.

Conflict of interest: none declared Financial support: none declared 